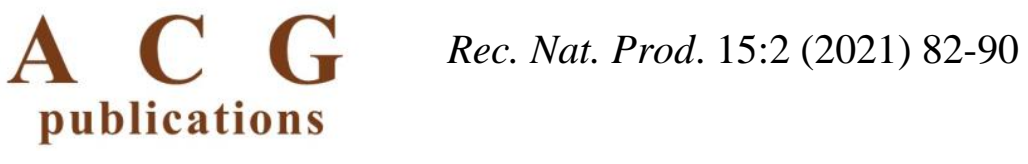

records of natural products

\title{
Identification and Structural Characterization of Anti-Endoplasmic Reticulum Stress Compounds from Ageratum conyzoides $(\mathbf{L}$.
}

\author{
Tran Duy Binh $\oplus^{1}$, Ryo Kusunoki ${ }^{1}$, Thanh Q. C. Nguyen $\oplus^{1}$, \\ Ako Nakagami $\odot{ }^{1}$, Kenji Kanaori ${ }^{1}$, Yen D. H. Nguyen ${ }^{1}$, \\ Tuan L. A. Pham ${ }^{1}$, Cuong C. Nguyen $\oplus^{1,2}$, Le Van Vang $\oplus^{1,2}$ \\ and Kaeko Kamei ${ }^{*}$ \\ ${ }^{1}$ Department of Functional Chemistry, Kyoto Institute of Technology, Kyoto, Japan \\ ${ }^{2}$ Department of Plant Protection, College of Agriculture Biology, Cantho University, Cantho, \\ Vietnam
}

(Received June 29, 2020; Revised August 14, 2020; Accepted August 16, 2020)

\begin{abstract}
Ageratum conyzoides is an herbaceous plant widely used in traditional medicine against various diseases, and possesses anti-inflammatory, anti-ulcer, analgesic, and diuretic properties. However, its effects on endoplasmic reticulum (ER) stress, as observed in diseases such as diabetes, have not yet been characterized. In this study, using mouse pancreatic $\beta$-cells, we demonstrated that the ethanol extract of $A$. conyzoides effectively suppressed cell death induced by ER stress. Four polymethoxyflavones (PMFs) including (1) 5,6,7,3',4',5'hexamethoxyflavone; (2) 5,6,7,8,3',4'-hexamethoxyflavone (nobiletin); (3) 3', $4^{\prime}$-methylenedioxy-5',5,6,7tetramethoxyflavone; and (4) 5,6,7,8,5'-pentamethoxy-3',4'-methylenedioxyflavone were isolated from the ethyl acetate fraction using reverse-phase chromatography. Their structures were elucidated using spectroscopic and mass-spectrometric analyses including 1D-, 2D-NMR, and HRESI-MS. All compounds were further evaluated for their ability to inhibit ER stress. Our results suggested that only compound $\mathbf{1}$ did not show an ability to rescue ER stress-induced cell death. Additionally, compound $\mathbf{2}$ as a nobiletin and its commercial product alleviated the tunicamycin-dependent chop mRNA expression induction. Notably, extremely low concentrations of both compounds exerted cytoprotective activity against tunicamycin-induced ER stress in pancreatic $\beta$-cells.
\end{abstract}

Keywords: Ageratum conyzoides; anti-endoplasmic reticulum stress; pancreatic $\beta$-cells; nobiletin. (C) 2020 ACG Publications. All rights reserved.

\section{Introduction}

Accumulating evidence has proven that endoplasmic reticulum (ER) stress plays a central role in the pathogenesis of various diseases such as diabetes, cancer, and neurodegeneration-related diseases. Therefore, regulating ER stress is crucial in controlling the progression of such diseases [1]. Type 2 diabetes mellitus (T2DM) is characterized by insulin resistance and the dysfunction of insulin producing $\beta$-cells in the islets of Langerhans of the pancreas [2,3]. Several studies have indicated that peripheral insulin resistance precedes hyperglycemia, eventually leading to T2DM [4-6]. There are

*Corresponding author: E-Mail: kame@kit.ac.jp ; Phone:081-075-724-7553 Fax:081-075-724-7553. 
two main stages in the progression of diabetes. Stage 1 is compensation: $\beta$-cell adaptation increases in the $\beta$-cell area to upregulate insulin secretion to increase insulin demand. Subsequently, stage 2 (i.e., decompensation stage) occurs when the $\beta$-cell area is reduced owing to the activation of cell death by higher ER and oxidative stress conditions [7,8]. The ER is known to be involved in the folding, modification, and trafficking of secretory and membrane proteins to the Golgi compartment [9]. Insulin is synthesized as preproinsulin in the ER of pancreatic $\beta$-cells. The removal of its signal peptide during insertion into the ER generates the mature zymogen proinsulin stored in secretory granules. It is secreted in response to increased blood glucose levels to maintain a normal blood glucose level. Insulin resistance causes $\beta$-cells to overproduce insulin, leading to elevated ER stress [10].

ER stress activates the unfolded protein response (UPR), whose outputs initially counter this stress. Over time, in the presence of a sustained stress signal, $\beta$-cells start to die via UPR-mediated apoptosis [1]. UPR is activated through three different signaling pathways involving the activation of the following three protein sensors: activating transcription factor 6 (ATF6), inositol-requiring enzyme 1 alpha (IRE1 $\alpha$ ), and PRKR-like ER kinase (PERK). ATF6 is transported to the Golgi apparatus and is translocated into the nucleus in its cleaved form, inducing the expression of transcription factors that regulate the overexpression of UPR elements [11]. In the absence of ER stress, IRE1 $\alpha$ is expressed in all cell types and under stress conditions; in an active form, IRE1 $\alpha$ catalyzes the splicing of X-boxbinding protein1 (XBP-1) mRNA to form the transcription factor XBP-1s, which is involved in the regulation of protein folding [12]. Furthermore, PERK-mediated UPR pathway activation induces eIF2 phosphorylation, which activates ATF4 and subsequently determines the upregulation of the proapoptotic factor CHOP; and CHOP expression is also increased by ATF6 [13].

Therapeutic interventions that increase the adaptation of the ER to stress and restore glucose hemostasis are a promising treatment for T2DM [14]. Recently, the screening of products obtained from natural sources has received increasing attention because they are generally considered less toxic with fewer side effects when compared to synthetic products. Interestingly, previous studies have indicated that natural compounds are effective against ER stress [15]. Hence, plant extracts have emerged as excellent candidates to isolate bioactive compounds that can be used for treating ER stress-related diseases. In this study, we screened various herbs used in traditional medicine to evaluate the anti-ER stress activity using the Mouse INsulinoma 6 (MIN6) cell line. Interestingly, Ageratum conyzoides (L.) exhibited remarkable effects against tunicamycin-induced ER stress and were further selected for isolation and identification of active components. The annual herb, $A$. conyzoides is commonly found in a specific part of Asia and in several tropical countries. It has been utilized in traditional medicinal remedies to treat various diseases, and possesses anti-inflammatory, anti-ulcer, analgesic, and diuretic properties [16]. The pharmacological activities of A. conyzoides are attributed to the presence of active ingredients such as flavonoids, alkaloids, and terpenoids [17]. A recent study reported that the leaf extract of A. conyzoides demonstrated antidiabetic and hypolipidemic characteristics in streptozotocin-induced diabetic rats [18]. Furthermore, another study indicated that the aqueous leaf extract of A. conyzoides also demonstrates hypoglycemic and kidney protection effects, given its ability to reduce serum glucose and creatinine levels in albino rats [19]. Altogether, our findings suggest that $A$. conyzoides and its active compounds exert anti-ER stress, which can be effective pharmacological agents in the treatment of diabetes.

\section{Materials and Methods}

\subsection{Plant Material and Extraction Procedures}

A. conyzoides were collected in Mekong delta, Vietnam, dried naturally, and ground with a waring blender. The plants were authenticated, and voucher specimens of all samples were deposited in Can Tho University, Vietnam. The dried powder was extracted with ethanol at $25{ }^{\circ} \mathrm{C}$ and centrifuged to obtain a supernatant. The residue was extracted for an additional three times, and the resulting supernatants were combined. The crude extract was concentrated under reduced pressure using a rotary evaporator (Rotavapor R-300; BUCHI, Flawil, Switzerland), freeze-dried, and then stored at $4{ }^{\circ} \mathrm{C}$ until further use. 


\subsection{Isolation of Anti-ER Stress Compounds from A. conyzoides}

The ethanol extract $(10 \mathrm{~g})$ of $A$. conyzoides was suspended in water $(500 \mathrm{~mL})$ and fractionated using hexane, chloroform, and ethyl acetate. The yield of each fraction was as follows: hexane fraction, $2.8 \mathrm{~g}$; chloroform fraction, $0.65 \mathrm{~g}$; ethyl acetate fraction, $0.45 \mathrm{~g}$; aqueous fraction, $6.1 \mathrm{~g}$.

The ethyl acetate fraction was dissolved in dimethyl sulfoxide (DMSO) $(10 \mathrm{mg} / \mathrm{mL})$ and further separated using reversed-phase high-performance liquid chromatography (HPLC) with LC-2130 pumps and a UV-Vis Detector L-2420 (Elite LaChrom; Hitachi High-Tech Science Corp., Tokyo, Japan). A Develosil ODS-5 column $(5 \mu \mathrm{m}, 4.6 \times 50 \mathrm{~mm}$ I.D.; Nomura Chemical Corp., Ltd., Kanagawa, Japan) was used with mobile phases of 5\% acetonitrile (phase A) and $90 \%$ acetonitrile (phase B). The sample was eluted using an 80 min linear gradient from mobile phase A to B with a 1 $\mathrm{mL} / \mathrm{min}$ flow rate. The sample was detected at $254 \mathrm{~nm}$. Lastly, $180 \mathrm{mg}$ of ethyl acetate fraction was subjected to HPLC. The yields for each compound obtained were $12 \mathrm{mg}$ (compound 1) and $9.6 \mathrm{mg}$ (compound 2), $0.32 \mathrm{mg}$ (compound 3) and $5.88 \mathrm{mg}$ (compound 4) corresponding to $66.7 \mathrm{mg}, 53.3 \mathrm{mg}$, $1.78 \mathrm{mg}$ and $32.7 \mathrm{mg}$ per $1 \mathrm{~g}$ of dried powder, respectively. The structures of those compounds elucidated by 1D and 2D NMR techniques and mass spectral data (see Supporting information) as

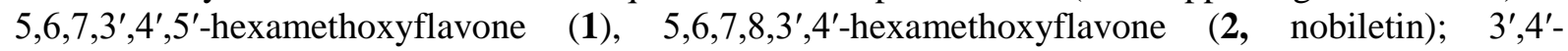
methylenedioxy-5',5,6,7-tetramethoxyflavone (3) and 5,6,7,8,5'-pentamethoxy-3',4'-methylenedioxyflavone (4).

The purity of each HPLC fraction was verified using thin-layer chromatography (TLC) with aluminum TLC plates coated in silica gel with fluorescent indicator F-254 (Merck, Darmstadt, Germany). The compounds were visualized by spraying with $10 \%(\mathrm{v} / \mathrm{v}) \mathrm{H}_{2} \mathrm{SO}_{4}$ in ethanol and heating for $5 \mathrm{~min}$ at $95^{\circ} \mathrm{C}$.

\subsection{Cell Culture and Cell Viability}

MIN6 cells, a mouse pancreatic $\beta$-cell line, was cultured in Dulbecco's Modified Eagle's Medium (DMEM; FUJIFILM-Wako, Japan) containing 10\% fetal bovine serum (FBS; GIBCO BRL, Grand Island, NY, USA), $1 \%$ L-glutamine, and $1 \mathrm{U} / \mathrm{mL}$ penicillin-streptomycin (FUJIFILM-Wako, Japan) in a humidified incubator with $5 \% \mathrm{CO}_{2}$ at $37^{\circ} \mathrm{C}$.

For the cell experiments, each A. conyzoides sample was dissolved in DMSO to obtain a stock. The stock solution was diluted to an appropriate concentration of samples with DMEM. This was added to the culture medium in 96-well plates and incubated for $24 \mathrm{~h}$. During treatment, the DMSO concentration was maintained at $0.1 \%(\mathrm{v} / \mathrm{v})$.

The cell viability was measured using a Cell Counting Kit-8 assay (CCK-8; Dojindo Molecular Technologies Inc., Rockville, USA) based on the measurement of intracellular dehydrogenase activity. Briefly, the cells were treated with extract in 96-well plates at a density of $2 \times 10^{5}$ cells/well for $24 \mathrm{~h}$, followed by incubation with extract and with or without tunicamycin (Tm; Wako, Osaka, Japan) for an additional $24 \mathrm{~h} \mathrm{[20].} \mathrm{After} \mathrm{that,} \mathrm{the} \mathrm{absorption} \mathrm{was} \mathrm{read} \mathrm{at} 450 \mathrm{~nm}$ using an SH-1200 microplate reader (CORONA Electric, Ibaraki, Japan). The concentrations of extract used in the assay are indicated in each figure legend.

\subsection{Quantitative Reverse Transcription PCR (RT-qPCR)}

MIN6 cells were incubated for $24 \mathrm{~h}$ in 6-well plates with extracts, washed with phosphatebuffered solution (PBS), and treated with extracts with or without Tm for a further $24 \mathrm{~h}$. The total RNA was extracted using TRIzol reagent (Invitrogen, Carlsberg, CA, USA), followed by purification using a Qiagen RNeasy Kit (Qiagen, Hilden, Germany). The cDNA was synthesized using Transcriptor Universal cDNA (Master Mix; Roche, Mannheim, Germany) and SimpliAmp ${ }^{\text {TM }}$ Thermal Cycler (Life Technologies, Singapore), according to the manufacturer's instructions. Quantitative PCR was performed using the FastStart Essential DNA Green Master Mix (Roche, Mannheim, Germany) and a Light-Cycler 96 (Roche). $\beta$-actin was used as a normalizing control, and the following primers were used in Table $\mathrm{S} 1$. 


\subsection{Nuclear magnetic Resonance (NMR) Spectrometry and Mass Spectrometry (MS) Analysis}

To elucidate the chemical structures, the isolated compounds were analyzed using NMR (Avance III-600 MHz, Bruker, Rheinstetten, Germany) with $\mathrm{CD}_{3} \mathrm{OD}$ and tetramethylsilane (TMS) as the solvent and internal standard, respectively. High-resolution electrospray ionization mass spectrometry (HR-ESI-MS) was performed using a MicrOTOF-Q mass spectrometer (Bruker, Rheinstetten, Germany).

\subsection{Statistical Analysis}

Experiments were repeated at least three times. All data are expressed as the mean \pm standard deviation (S.D.). Statistical significance was evaluated using one-way ANOVA, where $p<0.05$ was considered significant.

\section{Results and Discussions}

\subsection{Effect of A. conyzoides Extract on ER Stress in MIN6 Cells}

First, the cytotoxicity of ethanol extract of A. conyzoides (AC extract) was examined. MIN6 cells were treated with serial concentrations of AC extract for $24 \mathrm{~h}$, followed by the measurement of the cell viability. The cell viability as reduced substantially at AC extract concentrations higher than $1000 \mathrm{ng} / \mathrm{mL}$ (Figure 1A). Thus, the concentration of AC extract up to $100 \mathrm{ng} / \mathrm{mL}$ was used in further experiments.
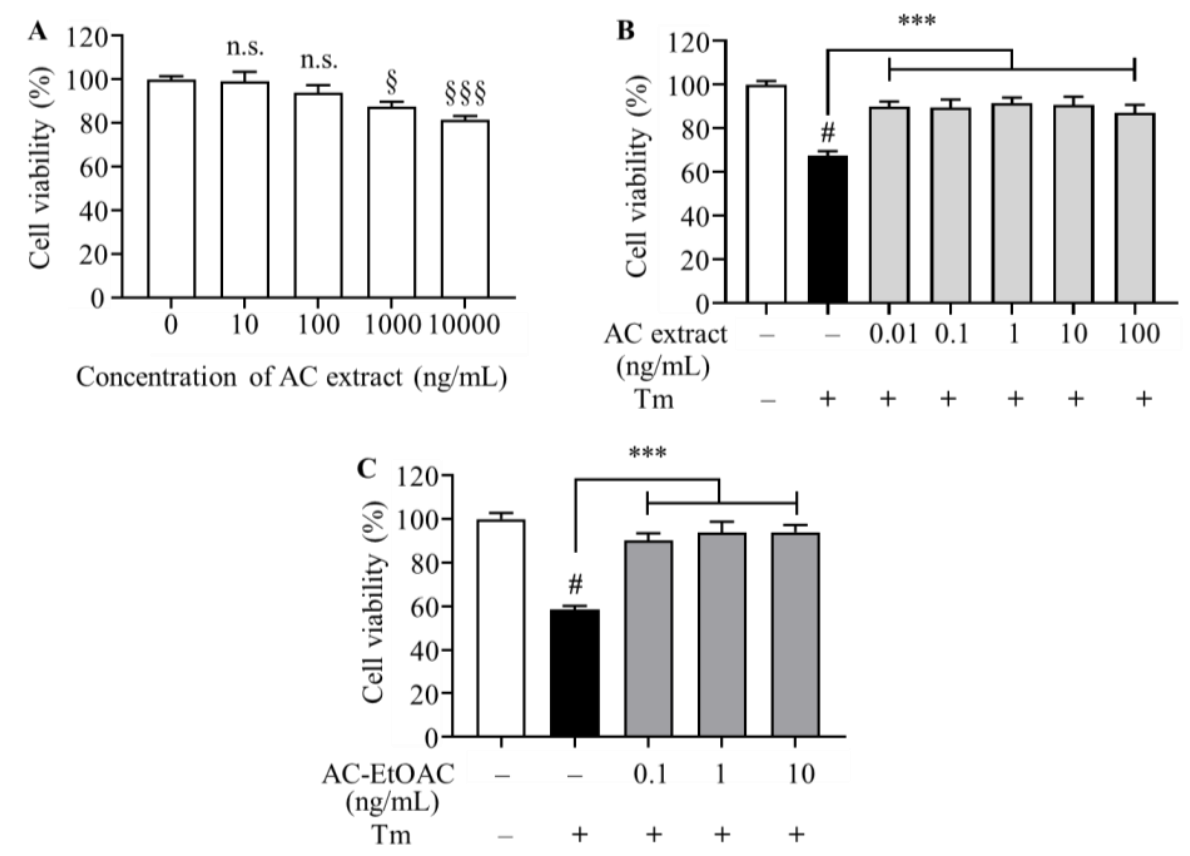

Figure 1. Cytotoxicity and anti-ER stress activity of Ageratum conyzoides extract. (A) MIN6 cells were treated with AC extract for $24 \mathrm{~h}$ before examining cell viability. (B) MIN6 cells were treated with AC extract, then co-treated with AC extract and/or $1 \mu \mathrm{M}$ Tm for $24 \mathrm{~h}$. (C) MIN6 cells were treated with AC- ethyl acetate (EtOAc) fraction for $24 \mathrm{~h}$, then co-treated with AC-EtOAc fraction and/or $1 \mu \mathrm{M}$ tunicamycin $(\mathrm{Tm})$ for an additional $24 \mathrm{~h}$. Cell viability was analyzed after treatment $(\mathrm{n}=$ 6). n.s., not significant; $\S, p<0.05$; $\S \S, p<0.01$; \#, $p<0.05$; ***, $p<0.01$. Data are expressed as the mean \pm S.D.

To evaluate the anti-ER stress capacity of A. conyzoides, MIN6 cells were treated with AC extract for $24 \mathrm{~h}$, followed by incubation with AC extract and with or without Tm for an additional 24 h. Tm is known to cause ER stress by blocking N-linked glycosylation (N-glycan), which leads to the production of unfolded proteins [21]. The cell viability was analyzed using a CCK-8 assay. As shown in Figure 1B, the cell viability improved significantly by treatment with AC extract $(0.01-100 \mathrm{ng} / \mathrm{mL})$ 
compared to Tm treatment alone. Moreover, the AC extract was also found to exert anti-ER stress effects on MIN6 cells using another ER-stress inducer, thapsigargin (data not shown).

The AC extract was separated into four fractions using hexane, chloroform, ethyl acetate, and water. After drying by evaporation and lyophilization, the four fractions were assayed for anti-ER stress activity. As shown in Figure 1C, the ethyl acetate fraction (AC-EtOAc fraction) significantly increased cell viability in MIN6 cells treated with Tm, indicating anti-ER stress activity. In contrast, the other three fractions were not effective against ER stress (data not shown).

RT-qPCR analysis was performed on ER stress makers including atf4, $x b p-1$, and chop, which induce apoptosis, proteasome expression, and chaperone expression [22]. As shown in Figure 2, the mRNA expression of these markers in MIN6 cells was induced by Tm treatment. However, this induction was suppressed significantly after treatment with the AC-EtOAc fraction, confirming the ability of A. conyzoides extract to alleviate ER stress.

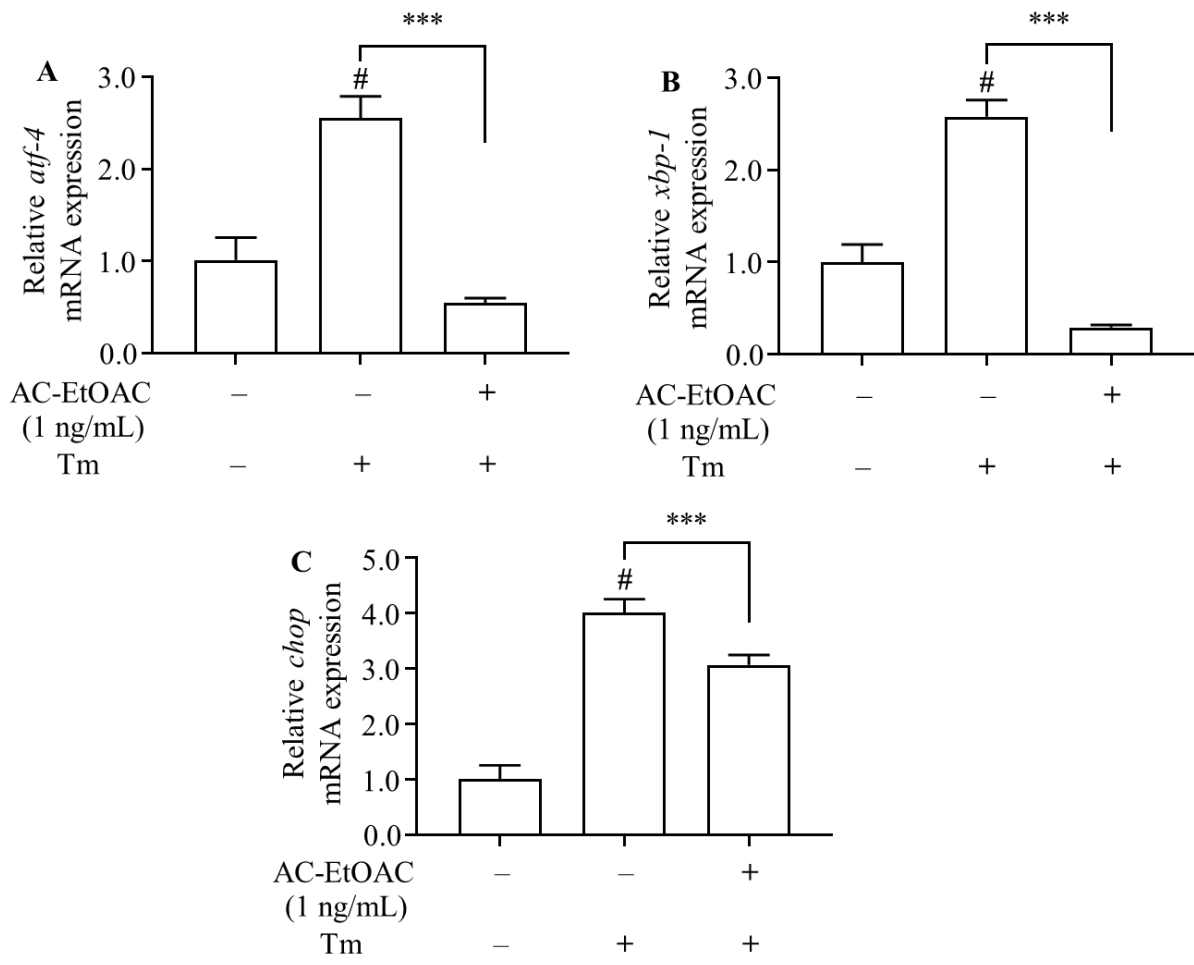

Figure 2. Effect of AC-EtOAc fraction on the expression of ER stress markers in MIN6 cells. The cells were treated with AC-EtOAc fraction for $24 \mathrm{~h}$, and then co-treated with AC-EtOAc and $1 \mu \mathrm{M}$ Tm for an additional $24 \mathrm{~h}$. The mRNA levels of atf-4 (A), xbp-1 (B), and chop (C) were detected using RT-qPCR after treatment $(\mathrm{n}=3)$. \#, $p<0.05 ; * * *, p<0.01$; Data are expressed as the mean \pm S.D.

\subsection{Isolation and Identification of Anti-ER Stress Compounds}

To identify the anti-ER stress compounds, the EtOAc fraction was further separated using reverse-phase HPLC. Four compounds, designated as 1, 2, 3, and $\mathbf{4}$ were collected. After verifying their purities using TLC, the compounds were analyzed using multistage MS, 1D NMR, and 2D NMR spectroscopy (Supporting Information). The ${ }^{1} \mathrm{H}$ NMR and ${ }^{13} \mathrm{C}$ NMR spectra were recorded and compared against the available literature. The data for identifying compounds is summarized in the Supporting Information, and the elucidated structures are shown in Figure 3. 
<smiles>COc1cc(-c2cc(=O)c3c(OC)c(OC)c(OC)cc3o2)cc(OC)c1OC</smiles><smiles>COc1ccc(-c2cc(=O)c3c(OC)c(OC)c(OC)c(OC)c3o2)cc1OC</smiles><smiles>COc1cc(-c2cc(=O)c3c(OC)c(OC)c(OC)cc3o2)cc2c1OCO2</smiles>

3<smiles>COc1cc(-c2cc(=O)c3c(OC)c(OC)c(OC)c(OC)c3o2)cc2c1OCO2</smiles>

Figure 3. Structures of flavonoids from the AC-EtOAc fraction

\subsection{Anti-ER Stress Activity of Isolated Compounds}

The anti-ER stress activity of the isolated compounds was evaluated by their effects on the viability of Tm-treated MIN6 cells. As shown in Figure 4A, compounds 2, 3, and 4 significantly suppressed Tm-induced cell death, whereas compound $\mathbf{1}$ did not. Since compound $\mathbf{2}$ was identical to nobiletin, the commercial product was investigated for its activity. The expression of chop is strongly stimulated by translocation of the transcriptional factors, XBP-1 and ATF-4, into the nucleus and aids in managing ER stress induced by unfolded and misfolded proteins [23]. Therefore, chop mRNA expression was chosen for the examination. As expected, commercial nobiletin suppressed cell death and induction of chop mRNA expression in MIN6 cells treated with Tm, as observed with compound $\mathbf{2}$ (Figure 4B). These results indicate that compound $\mathbf{2}$ (nobiletin), 3, and $\mathbf{4}$ in A. conyzoides can exert cytoprotective activity against ER stress.
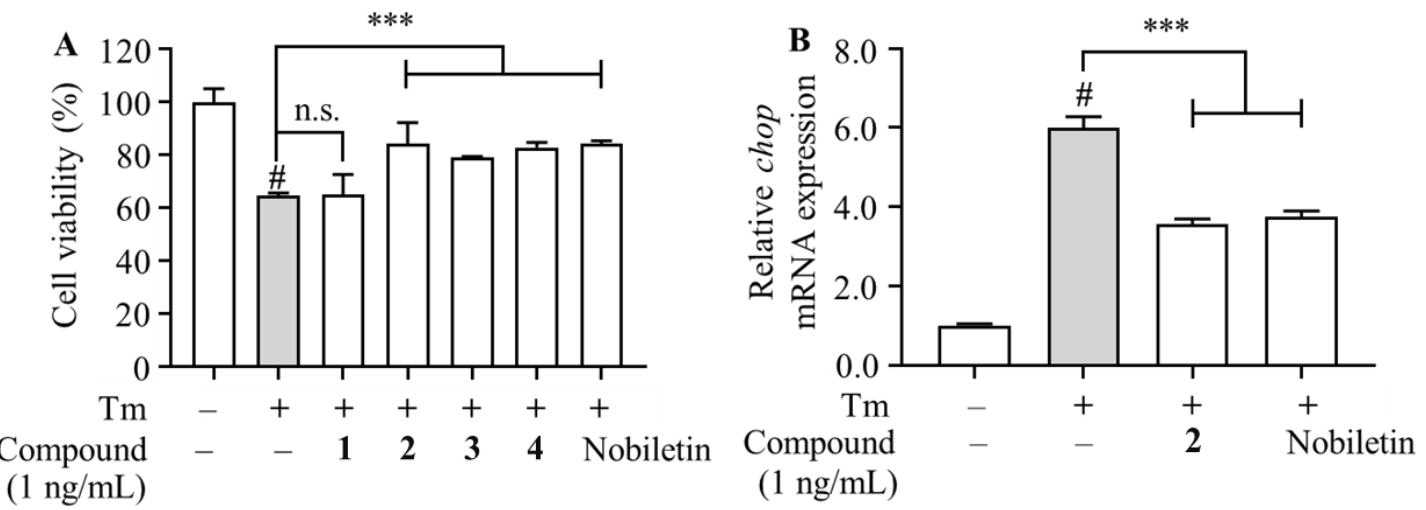

Figure 4. Anti-ER stress activities of isolated compounds in MIN6 cells. The cells were treated with compounds $1,2,3,4$, or nobiletin for $24 \mathrm{~h}$, then co-treated with each compound and $1 \mu \mathrm{M} \mathrm{Tm}$ for an additional $24 \mathrm{~h}$. The cell viability (A) and mRNA levels of chop (B) were analyzed after treatment (n =6). n.s.; not significant; \#, $p<0.01 ; * * *, p<0.01$; Data are expressed as the mean \pm S.D.

In this study, anti-ER stress compounds were isolated from A. conyzoides and identified. By examining their cytoprotective effects, we found that nobiletin, $\mathbf{3}$, and $\mathbf{4}$ exerted a protective effect on pancreatic $\beta$-cells against ER stress (Figure 3B). Structural analyses using NMR and MS suggested that these compounds were polymethoxyflavones. Although not yet fully understood, the metabolites of polymethoxyflavones have been previously studied. These have been found to undergo in vivo biotransformation, producing metabolites with different bioactivities and pharmacological properties 
[24]. Compound $\mathbf{3}$ showed stronger activity levels when compared to compound $\mathbf{4}$, suggesting that a methoxy group at the 8-position in ring A might be a critical factor for ER stress-suppressing activity (Figure 4). This was supported by comparing the activities of compound $\mathbf{2}$ (nobiletin) and compound 1. Consequently, non-active compound $\mathbf{1}$ and active compound $\mathbf{3}$ were found to possess structural differences between the methoxy and methylenedioxy groups $\left(-\mathrm{O}-\mathrm{CH}_{2}-\mathrm{O}-\right)$ at the substituents at positions $4^{\prime}$ and $5^{\prime}$. This implies that the presence of a methylenedioxy group also enables anti-ER stress activity. Thus, the presence of a methoxy group at position- 8 of ring A and a methylenedioxy group (-O- $\left.\mathrm{CH}_{2}-\mathrm{O}-\right)$ at the positions $4^{\prime}$ and $5^{\prime}$ of ring $\mathrm{B}$ are critical structural factors for anti-ER stress activity.

In this study, nobiletin was demonstrated to possess anti-ER stress activity. Nogata et al. (2006) reported that nobiletin is one of the most common ingredients in citrus fruits [25]. It exerts numerous effects against inflammation, dermatitis, hepatitis, and prevents the spread of tumors and metastasis [26-29]. Furthermore, nobiletin has been previously found to reduce amyloid- $\beta$ inside and outside iPS cell-derived Alzheimer's model neurons [30]. Another study indicated that nobiletin $(100 \mu \mathrm{M})$ is capable of attenuating apoptosis in human choriocarcinoma trophoblast cells (BeWo cells), which may help prevent pregnancy-related diseases caused by apoptosis [31]. Meanwhile, nobiletin $(12.5-50 \mu \mathrm{M})$ has also been reported to induce apoptosis in human gastric cancer SNU-16 cells through pathways involving intracellular ER stress-mediated protective autophagy [32]. In general, within the test dose range of nobiletin, the apoptosis process of tumor cells was enhanced with increasing concentrations of nobiletin. However, a recent study observed that the apoptosis of cancer cells was promoted by a low concentration of nobiletin $(40 \mu \mathrm{M})$, while it was not altered at higher doses $(60$ or $100 \mu \mathrm{M})$ [33,34]. Remarkably, our results show that three compounds isolated from A. conyzoides protected $\beta$ cells against Tm-induced ER stress at extremely low concentrations, especially nobiletin $(1 \mathrm{ng} / \mathrm{mL}$ or $2.5 \mathrm{nM}$ ). Notably, our data revealed that crude extract, EtOAc fraction, and isolated compounds of $A$. conyzoides at the same concentration could remedy the cell death induced by ER stress with a similar trend. These phenomena may be due to the high amounts of active compounds in the extract and its EtOAc fraction, or from the results of the sum of cytotoxic and cytoprotective effects. At high concentration of AC extract, cell death was induced (Figure 1A). This is consistent with a previous study, which demonstrated that this plant possesses toxicity [35], suggesting that low concentrations of $\mathrm{AC}$ are more effective and safe for humans. Thus, the present study demonstrated a new protective function of nobiletin and two other polymethoxyflavones against pancreatic $\beta$-cells from Tm-induced ER stress, enabling cell death suppression.

In conclusion, ER stress is involved in various diseases other than diabetes, including neurodegenerative disease, cancer, hypertension, and kidney dysfunction. Therefore, this study provides important insights into the development of treatments for many diseases. However, further studies are needed to elucidate the mechanism underlying the effect of the identified compounds against ER stress in pancreatic $\beta$-cells.

\section{Acknowledgments}

This work was supported by Grants-in-Aid from JSPS Core-to-Core program.

\section{Supporting Information}

Supporting information accompanies this paper on http://www.acgpubs.org/journal/records-of$\underline{\text { natural-products }}$

\section{ORCID}

Tran Duy Binh: 0000-0003-1591-2611

Ryo Kusunoki: 0000-0001-5037-6995

Thanh Q. C. Nguyen: 0000-0001-5128-4654

Ako Nakagami: $\underline{0000-0001-7946-6636}$

Kenji Kanaori: 0000-0002-0142-9613

Yen D. H. Nguyen: 0000-0001-7094-5526

Tuan L. A. Pham: 0000-0001-8524-049X 
Cuong C. Nguyen: 0000-0002-3139-217X

Le Van Vang: 0000-0002-4658-9442

Kaeko Kamei: 0000-0002-7496-4692

\section{References}

[1] J.H. Lin, P. Walter and T.S.B. Yen (2008). Endoplasmic reticulum stress in disease pathogenesis, Annu. Rev. Pathol. 3, 399-425.

[2] C.J. Rhodes (2005). Type 2 diabetes-a matter of beta-cell life and death?, Science 307, 380-384.

[3] B. Horváth, P. Mukhopadhyay, G. Haskó and P. Pacher (2012). The endocannabinoid system and plantderived cannabinoids in diabetes and diabetic complications, Am. J. Clin. Pathol. 180, 432-442.

[4] C. Hansawasdi and J. Kawabata (2006). $\alpha$-Glucosidase inhibitory effect of mulberry (Morus alba) leaves on Caco-2, Fitoterapia 77, 568-573.

[5] M. Prentki and C.J. Nolan (2006). Islet $\beta$-cell failure in type 2 diabetes, J. Clin. Invest. 116, $1802-1812$.

[6] Q. Liu, X. Li, C. Li, Y. Zheng, F. Wang, H. Li and G. Peng (2016). 1-Deoxynojirimycin alleviates liver injury and improves hepatic glucose metabolism in db/db mice, Molecules 21, 279.

[7] G.C. Weir and S. Bonner-Weir (2004). Five stages of evolving $\beta$-cell dysfunction during progression to diabetes, Diabetes 53, S16-21.

[8] G.C. Weir, D.R. Laybutt, H. Kaneto, S. Bonner-Weir and A. Sharma (2001). Beta-cell adaptation and decompensation during the progression of diabetes, Diabetes 50, S154-159.

[9] L. Szablewski (2014). Diabetes mellitus: influences on cancer risk, Diabetes Met Res. Rev. 30, $543-553$.

[10] V.A. Fonseca (2009). Defining and characterizing the progression of type 2 diabetes, Diabetes Care. 32, S151-156.

[11] R. Asada, S. Kanemoto, S. Kondo, A. Saito and K. Imaizumi (2011). The signalling from endoplasmic reticulum-resident bZIP transcription factors involved in diverse cellular physiology, J. Biochem. 149, 507-518.

[12] M.K. Shahrestanaki, F.P. Arasi and M. Aghaei (2019). Adenosine protects pancreatic $\beta$-cells against apoptosis induced by endoplasmic reticulum stress, J. Cell. Biochem. 120, 7759-7770.

[13] J.X.H. Goh, L.T.H. Tan, J.K. Goh, K.G. Chan, P. Pusparajah, L.H. Lee and B.H. Goh (2019). Nobiletin and derivatives: functional compounds from citrus fruit peel for colon cancer chemoprevention, Cancers 11, 86711 .

[14] S.H. Back and R.J. Kaufman (2012). Endoplasmic reticulum stress and type 2 diabetes, Annu. rev. Biochem. 81, 767-793.

[15] P. Limonta, R.M. Moretti, M. Marzagalli, F. Fontana, M. Raimondi and M. Montagnani Marelli (2019). Role of endoplasmic reticulum stress in the anticancer activity of natural compounds, Int. J. Mol. Sci. 20, 961.

[16] B.K.F.P. Kouame, D. Toure, A.L.C. Kablan, S.G. Bedi, I. Tea, R.J. Robins, J.C. Chalchat and Z.F. Tonzibo (2017). Chemical constituents and antibacterial activity of essential oils from flowers and stems of Ageratum conyzoides from ivory coast, Rec. Nat. Prod. 12, 160-168.

[17] N. Yadav, S.A. Ganie, B. Singh, A.K. Chhillar and S.S. Yadav (2019). Phytochemical constituents and ethnopharmacological properties of Ageratum conyzoides L., Phytother Res. 33, 2163-2178.

[18] K.N. Agbafor, S.C. Onuohah, M.C. Ominyi and O.F. Orinya (2015). Alum, antidiabetic, hypolipidemic and antiathrogenic properties of leaf extracts of Ageratum conyzoides in Streptozotocin-induced diabetic rats, Int. J. Curr. Microbiol. App. Sci. 4, 816-824.

[19] K.N. Agbafor, A.G. Engwa, C.M. Ude, I.K. Obiudu and B.O. Festus (2015). The effect of aqueous leaf extract of Ageratum conyzoides on blood glucose, creatinine and calcium ion levels in albino rats, Res. $j$. 3, 408-415.

[20] T. Nakagawa, H. Zhu, N. Morishima, E. Li, J. Xu, B.A. Yankner and J. Yuan (2000). Caspase-12 mediates endoplasmic-reticulum-specific apoptosis and cytotoxicity by $\beta$-amyloid, Nature 403, 98-103.

[21] L. Lehle and W. Tanner (1976). The specific site of tunicamycin inhibition in the formation of dolicholbound N-acetylglucosamine derivatives, FEBS Lett. 71, 167-170.

[22] C.M. Oslowski and F. Urano (2011). Measuring ER stress and the unfolded protein response using mammalian tissue culture system, Methods Enzymolog. 490, 71-92.

[23] A.H. Schönthal (2012). Endoplasmic reticulum stress: its role in disease and novel prospects for therapy, Scientifica 2012, 857516.

[24] K. Youn, Y. Yu, J. Lee, W.-S. Jeong, C.-T. Ho and M. Jun (2017). Polymethoxyflavones: novel $\beta$ secretase (BACE1) inhibitors from citrus peels, Nutrients 9, 95-101.

[25] Y. Nogata, K. Sakamoto, H. Shiratsuchi, T. Ishii, M. Yano and H. Ohta (2006). Flavonoid composition of fruit tissues of citrus species, Biosci. Biotech. Bioch. 70, 178-192. 
[26] A. Minagawa, Y. Otani, T. Kubota, N. Wada, T. Furukawa, K. Kumai, K. Kameyama, Y. Okada, M. Fujii, M. Yano, T. Sato, A. Ito and M. Kitajima (2001). The citrus flavonoid, nobiletin, inhibits peritoneal dissemination of human gastric carcinoma in SCID mice, Japan. J. Cancer Res: Gann. 92, $1322-1328$.

[27] T. Sato, L. Koike, Y. Miyata, M. Hirata, Y. Mimaki, Y. Sashida, M. Yano and A. Ito (2002). Inhibition of activator protein-1 binding activity and phosphatidylinositol 3-kinase pathway by nobiletin, a polymethoxy flavonoid, results in augmentation of tissue inhibitor of metalloproteinases-1 production and suppression of production of matrix metalloproteinases-1 and - 9 in human fibrosarcoma HT-1080 cells, Cancer Res. 62, 1025-1029.

[28] S. Tanaka, T. Sato, N. Akimoto, M. Yano and A. Ito (2004). Prevention of UVB-induced photoinflammation and photoaging by a polymethoxy flavonoid, nobiletin, in human keratinocytes in vivo and in vitro, Biochem. Pharmacol. 68, 433-439.

[29] N. Yoshimizu, Y. Otani, Y. Saikawa, T. Kubota, M. Yoshida, T. Furukawa, K. Kumai, K. Kameyama, M. Fujii, M. Yano, T. Sato, A. Ito and M. Kitajima (2004). Anti-tumor effects of nobiletin, a citrus flavonoid, on gastric cancer include: antiproliferative effects, induction of apoptosis and cell cycle deregulation, Aliment. Pharm. Ther. 20, 95-101.

[30] J. Kimura, K. Shimizu, K. Kajima, A. Yokosuka, Y. Mimaki, N. Oku and Y. Ohizumi (2018). Nobiletin reduces intracellular and extracellular $\beta$-amyloid in IPS cell-derived Alzheimer's disease model neurons, Biol. Pharm. Bull. 41, 451-457.

[31] M. Zhang, R. Zhang, J. Liu, H. Wang, Z. Wang, J. Liu, Y. Shan and H. Yu (2020). The effects of $5,6,7,8,3^{\prime}, 4^{\prime}$-hexamethoxyflavone on apoptosis of cultured human choriocarcinoma trophoblast cells, Molecules 25, 946.

[32] J.Y. Moon and S.K. Cho (2016). Nobiletin induces protective autophagy accompanied by er-stress mediated apoptosis in human gastric cancer SNU-16 cells, Molecules 21, 914.

[33] X. Wu, M. Song, M. Wang, J. Zheng, Z. Gao, F. Xu, G. Zhang and H. Xiao (2015), Chemopreventive effects of nobiletin and its colonic metabolites on colon carcinogenesis, Mol. Nutr. Food. Res. 59, 23832394.

[34] K.L. Morley, P.J. Ferguson and J. Koropatnick (2007). Tangeretin and nobiletin induce G1 cell cycle arrest but not apoptosis in human breast and colon cancer cells, Cancer Lett. 251, 168-178.

[35] H. Wiedenfeld (2011). Plants containing pyrrolizidine alkaloids: toxicity and problems, Food. Addit. \& Contam. A. 28, 282-292.

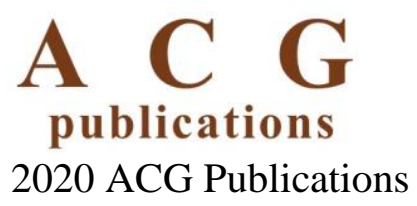

